\title{
Caracterização microbiológica e físico-química do leite cru refrigerado durante o tempo de armazenamento na propriedade
}

\author{
[Microbiological and physicochemical characterization of refrigerated raw milk \\ during storage in the farm]
}

\section{"Artigo Científico/Scientific Article"}

\author{
Adriane Ferreira Frizzo, Daniela Andrighi, Karina Ramirez Starikoff*
}

Universidade Federal da Fronteira Sul, Realeza-PR, Brasil.

*Autor para correspondência/Corresponding author: E-mail: karina.starikoff@uffs.edu.br

\begin{abstract}
Resumo
No presente trabalho objetivou-se avaliar a qualidade microbiológica e físico-química do leite cru refrigerado proveniente de 10 propriedades leiteiras do município de Realeza - PR. Foram realizadas análises microbiológicas de contagem de microrganismos aeróbios mesófilos, psicrotróficos, colônias proteolíticas e lipolíticas e análises físico-químicas de $\mathrm{pH}$, densidade, acidez Dornic, extrato seco, gordura e proteína. Os resultados obtidos foram submetidos à análise estatística de Tukey a 5\%. As principais alterações físicoquímicas observadas nas amostras avaliadas foram a diminuição do $\mathrm{pH}$, o aumento da acidez Dornic e a diminuição nos teores de gordura da primeira para a segunda coleta em algumas amostras. Quanto às contagens de microrganismos, os aeróbios mesófilos se mantiveram dentro do estabelecido na legislação vigente. Enquanto nos psicrotróficos, e nas colônias proteolíticas e lipolíticas de algumas amostras o crescimento foi superior ao recomendado pela literatura. Conclui-se que as amostras avaliadas apresentaram poucas alterações microbiológicas e físico-químicas durante o período de armazenamento, porém é de grande importância a análise frequente do leite em busca de microrganismos que possam alterar a sua composição.palavras
\end{abstract}

Palavras-chave: aeróbios mesófilos; lipolíticos; proteolíticos; psicrotróficos; qualidade.

\begin{abstract}
The present work had as objective to evaluate the microbiological and physicochemical quality of the refrigerated raw milk obtained in 10 dairy farms from the city of Realeza - PR. Microbiological counts of mesophilic aerobic microorganisms, psychrotrophic, proteolytic, and lipolytic colonies were performed. Physicochemical analyses of $\mathrm{pH}$, density, Dornic acidity, dry extract, fat, and protein were also done. The results of these were submitted to statistical analysis using Tukey at 5\%. The main physicochemical changes in the milk were the decrease in $\mathrm{pH}$, the increase in Dornic acidity, and also a decrease in the fat contents from the first to the second collection in some samples. Regarding the microorganism counts, the mesophilic aerobes remained within the established in the current legislation. In the counts of psychrotrophic, proteolytic, and lipolytic colonies there were samples that exceeded the recommendation in the literature. It was concluded that there were few microbiological and physicochemical changes in the milk evaluated during the period of storage in the 10 properties evaluated, however, the frequent analysis of the milk in search of microorganisms that can alter its composition is of great importance.
\end{abstract}

Keywords: mesophilic aerobes; lipolytic; proteolytic; psychrotrophic; quality.

\section{Introdução}

De acordo com o Instituto Brasileiro de Geografia e Estatística (IBGE) em 2015 a produção leiteira do Brasil foi de 35.000.227 milhões de litros de leite (IBGE, 2015; SEAB, 2017a). O

Estado do Paraná é o segundo maior produtor do país e sua produção de leite em 2015 foi de 4.660.174 milhões de litros de leite (IBGE, 2015; SEAB, 2017a). A mesorregião Sudoeste do estado 
do Paraná é considerada a segunda maior bacia leiteira do Estado, atrás ainda da região Oeste, com uma produção de 1.099 .509 milhão no ano de 2015 (IBGE, 2015; SEAB, 2017b).

A região Sudoeste do Paraná tem como característica que grande parte da produção de leite é realizada pela agricultura familiar. Um aspecto de grande preocupação nesse cenário é a falta de mão de obra especializada e escasso conhecimento sobre boas práticas no processo de ordenha (Pin et al., 2014). O resultado é um produto com baixa qualidade microbiológica e físico-química, baixa produtividade e lucratividade.

Um dos maiores avanços para o aumento da qualidade do leite produzido no país foi através de sua regulamentação. Atualmente, a Instrução Normativa ${ }^{\circ} 62$ de 2011 - IN62/2011 (BRASIL, 2011) do Ministério da Agricultura Pecuária e Abastecimento (MAPA), que altera a IN51/2002, estabelece a refrigeração do leite cru a $4^{\circ} \mathrm{C}$ e seu armazenamento na propriedade rural por um período máximo de 48 horas. O leite é submetido à refrigeração com o intuito de controlar a multiplicação de bactérias aeróbias mesófilas, cuja contagem evidencia as condições de higiene até o momento da ordenha, se houver o bom funcionamento do sistema de refrigeração do leite (Izidoro et al., 2013).

Entretanto, na faixa de temperatura de refrigeração ocorre seleção térmica a multiplicação de outro grupo de bactérias, as psicrotróficas (Moreira e Montanhini, 2014). Os microrganismos psicrotróficos possuem a capacidade de multiplicação a $7^{\circ} \mathrm{C}$ ou temperaturas mais baixas, mesmo não sendo temperaturas ideais para sua multiplicação, e apresentam capacidade de produzir enzimas lipolíticas e proteolíticas termoestáveis (Vidal-Martins et al., 2005; Pinto et al., 2006; Reis et al., 2013).

Considera-se que a presença de psicrotróficos em concentrações superiores a 1.000.000 $\left(10^{6}\right)$ unidades formadoras de colônias por mililitro $(\mathrm{UFC} / \mathrm{mL})$ está relacionada à presença das enzimas lipolíticas e proteolíticas e aos produtos de sua ação (Vidal-Martins et al., 2005; Pinto et al., 2006; Reis et al., 2013). De acordo com Griffiths (1989) essas enzimas são produzidas principalmente no final da fase logarítmica $(\log )$ de multiplicação e, além de se desenvolverem em temperaturas de refrigeração, podem manter de $30 \%$ a $100 \%$ de sua atividade após tratamentos térmicos como pasteurização e UHT (Cousin, 1982). Segundo Ângelo et al. (2014) elas diminuem a concentração de proteína e gordura do leite em cerca de $10 \%$, e, também, diminuem a vida de prateleira, alteram sabor, odor e aparência do leite e produtos derivados (Nörnberg et al., 2010; Reis et al., 2013).

Assim, o presente trabalho teve como objetivo avaliar a qualidade microbiológica e físico-química do leite produzido em propriedades da Agricultura Familiar na cidade de Realeza Paraná durante o período de armazenamento na propriedade.

\section{Material e Métodos}

Foram coletadas amostras de leite cru refrigerado do tanque de armazenamento de 10 propriedades leiteiras localizadas no município de Realeza - Paraná no período de fevereiro e julho de 2017. As propriedades foram caracterizadas como de agricultura familiar, com número de animais variando de 20 a 60 e produção de leite por vaca em lactação por dia varia de baixa (até 10 litros/vaca/dia) a média (10 a 20 litros/vaca/dia) (IPARDES, 2008).

Realizaram-se duas coletas por propriedade, totalizando 20 amostras. A primeira coleta foi realizada após a primeira ordenha que sucede a coleta do leite pelo caminhão. A segunda coleta foi realizada com 48 horas após a primeira, totalizando quatro ordenhas. Foi realizada a aferição da temperatura do leite antecedendo as coletas, após homogeneização no tanque, com termômetro digital tipo espeto.

As amostras eram coletadas após homogeneização do leite e utilizando concha previamente esterilizada. Foram coletados cerca de $500 \mathrm{~mL}$ de leite, acondicionado em frasco previamente esterilizado e lacrado até o momento da coleta. Para o transporte das amostras, os frascos eram acondicionados em caixa isotérmica com gelo reciclável. As amostras eram levadas aos laboratórios da Universidade Federal da Fronteira Sul - Campus Realeza para processamento imediato ou até o período de 12 horas, para análises microbiológicas e físico-químicas respectivamente.

Para as análises microbiológicas foi realizada a diluição seriada em solução salina peptonada estéril a $0,1 \%$, até a diluição de $10^{-3}$. A contagem de microrganismos aeróbios mesófilos seguiu conforme IN62/2003 (BRASIL, 2003), com plaqueamento em ágar padrão para contagem (PCA) em duplicata pelo método em profundidade (pour plate), com posterior incubação a $37^{\circ} \mathrm{C}$ por 
48 horas. Para a contagem de bactérias psicrotróficas, o plaqueamento foi feito em superfície no ágar PCA, também em duplicata, com posterior incubação a $7^{\circ} \mathrm{C}$ por 10 dias (Silva et al., 2007).

A avaliação da presença de enzimas proteolíticas foi realizada através do plaqueamento em superfície em ágar leite, preparado com PCA suplementado com $10 \%$ de leite desnatado, em duplicata, e posterior incubação a $20^{\circ} \mathrm{C}$ por 72 horas (Marcy e Pruett, 2001). A presença de enzimas lipolíticas foi avaliada pelo plaqueamento em superfície em ágar tributirina, preparado com ágar tributirina suplementado com $1 \%$ de tributirina, em duplicata, e posterior incubação a $20^{\circ} \mathrm{C}$ por 72 horas (Hass, 2001).

Para o cálculo dos resultados seguiu-se o disposto na IN62/2003 (BRASIL, 2003). Foram consideradas as diluições com número de colônias entre 25 e 250 , foi feito o cálculo de colônias por placas, em seguida a média e o resultado foi expresso em UFC/mL (Silva et al., 2007).

As análises físico-químicas foram realizadas de acordo com a Instrução Normativa $N^{\circ} 68-$ IN68/2006 (BRASIL, 2006) que dispõe sobre os métodos oficiais. As análises de densidade, $\mathrm{pH}$, acidez, sólidos totais, gordura e proteína foram realizadas em duplicata. A densidade foi avaliada pelo uso de termolactodensímetro, com posterior correção de acordo com a temperatura. $\mathrm{O}$ pH foi avaliado utilizando pHmetro calibrado com soluções tampão. A acidez do leite foi avaliada através de titulação com solução Dornic (hidróxido de sódio N/9). Os sólidos totais foram avaliados pelo extrato seco a $105^{\circ} \mathrm{C}$. A proteína do leite foi avaliada pela técnica do nitrogênio total. A gordura foi avaliada pelo método butirométrico (Castanheira, 2012).

Os valores unitários das análises microbiológicas e físico-químicas foram tabulados em planilhas, para cálculo das médias. Os valores das análises físico-químicas ainda foram submetidos à análise de variância. Utilizou-se o teste de Tukey em ambos, através do programa Sisvar for Windows 5.3 Build 77 (Ferreira, 2014).

\section{Resultados}

Na tabela 1 observam-se as contagens de microrganismos mesófilos, psicrotróficos, colônias proteolíticas e lipolíticas expressas em UFC/mL.

Os resultados das análises físico-químicas encontradas no leite cru refrigerado, em ambas as coletas, podem ser observados na tabela 2 .

Tabela 1. Resultados microbiológicos do leite cru refrigerado durante o tempo de armazenamento na propriedade.

\begin{tabular}{ccccccccc}
\hline & \multicolumn{2}{c}{ Aeróbios Mesófilos } & \multicolumn{2}{c}{ Psicrotróficos } & \multicolumn{2}{c}{ Proteolíticos } & \multicolumn{2}{c}{ Lipolíticos } \\
\cline { 2 - 8 } $\mathbf{P}$ & Antes & Depois & Antes & Depois & Antes & Depois & Antes & Depois \\
\hline $\mathbf{1}$ & $6,5.10^{2} \mathrm{a}$ & $2,5.10^{5} \mathrm{~b}$ & $8,8.10^{4} \mathrm{a}$ & $3,4.10^{6} \mathrm{~b}$ & $2,0.10^{4} \mathrm{a}$ & $9,0.10^{5} \mathrm{~b}$ & $2,2.10^{5} \mathrm{a}$ & $1,3.10^{6} \mathrm{~b}$ \\
$\mathbf{2}$ & $5,6.10^{3} \mathrm{a}$ & $1,5.10^{3} \mathrm{a}$ & $6,9.10^{4} \mathrm{a}$ & $7,3.10^{5} \mathrm{a}$ & $3,5.10^{4} \mathrm{a}$ & $4,0.10^{3} \mathrm{a}$ & $4,4.10^{5} \mathrm{a}$ & $6,9.10^{5} \mathrm{a}$ \\
$\mathbf{3}$ & $5,3.10^{2} \mathrm{a}$ & $4,0.10^{2} \mathrm{a}$ & $7,0.10^{3} \mathrm{a}$ & $2,0.10^{5} \mathrm{a}$ & $2,5.10^{3} \mathrm{a}$ & $6,0.10^{4} \mathrm{a}$ & $1,4.10^{5} \mathrm{a}$ & $7,6.10^{5} \mathrm{a}$ \\
$\mathbf{4}$ & $5,7.10^{2} \mathrm{a}$ & $4,5.10^{2} \mathrm{a}$ & $1,6.10^{4} \mathrm{a}$ & $1,0.10^{4} \mathrm{a}$ & $4,0.10^{3} \mathrm{a}$ & $2,9.10^{3} \mathrm{a}$ & $8,8.10^{3} \mathrm{a}$ & $7,0.10^{3} \mathrm{a}$ \\
$\mathbf{5}$ & $9,8.10^{3} \mathrm{a}$ & $1,9.10^{3} \mathrm{a}$ & $9,0.10^{3} \mathrm{a}$ & $5,7.10^{4} \mathrm{a}$ & $4,5.10^{4} \mathrm{a}$ & $9,0.10^{3} \mathrm{a}$ & $8,8.10^{3} \mathrm{a}$ & $2,0.10^{4} \mathrm{a}$ \\
$\mathbf{6}$ & $1,0.10^{5} \mathrm{a}$ & $1,6.10^{4} \mathrm{~b}$ & $7,0.10^{5} \mathrm{a}$ & $1,3.10^{6} \mathrm{a}$ & $6,0.10^{5} \mathrm{a}$ & $1,6.10^{4} \mathrm{~b}$ & $1,0.10^{6} \mathrm{a}$ & $2,1.10^{5} \mathrm{~b}$ \\
$\mathbf{7}$ & $9,0.10^{2} \mathrm{a}$ & $8,3.10^{3} \mathrm{a}$ & $2,8.10^{6} \mathrm{a}$ & $9,0.10^{5} \mathrm{~b}$ & $1,1.10^{6} \mathrm{a}$ & $7,8.10^{5} \mathrm{~b}$ & $7,5.10^{5} \mathrm{a}$ & $1,0.10^{6} \mathrm{a}$ \\
$\mathbf{8}$ & $2,9.10^{2} \mathrm{a}$ & $7,0.10^{2} \mathrm{a}$ & $2,4.10^{5} \mathrm{a}$ & $2,6.10^{5} \mathrm{a}$ & $1,9.10^{5} \mathrm{a}$ & $1,1.10^{6} \mathrm{~b}$ & $1,1.10^{6} \mathrm{a}$ & $1,2.10^{6} \mathrm{a}$ \\
$\mathbf{9}$ & $6,2.10^{2} \mathrm{a}$ & $1,5.10^{3} \mathrm{a}$ & $7,0.10^{4} \mathrm{a}$ & $6,0.10^{4} \mathrm{a}$ & $2,0.10^{4} \mathrm{a}$ & $5,8.10^{3} \mathrm{a}$ & $6,0.10^{4} \mathrm{a}$ & $1,1.10^{5} \mathrm{a}$ \\
$\mathbf{1 0}$ & $1,6.10^{3} \mathrm{a}$ & $2,0.10^{2} \mathrm{a}$ & $4,0.10^{3} \mathrm{a}$ & $4,0.10^{3} \mathrm{a}$ & $4,5.10^{3} \mathrm{a}$ & $1,0.10^{4} \mathrm{a}$ & $3,9.10^{3} \mathrm{a}$ & $1,7.10^{4} \mathrm{~b}$ \\
\hline
\end{tabular}

Legenda: P: Propriedades. Resultados em UFC/mL.

\section{Discussão}

O valor estipulado pela IN 62/2011 para bactérias aeróbias mesófilas, a partir de 2016, seria de, no máximo, $1,0.10^{5} \mathrm{UFC} / \mathrm{mL}$, com no mínimo uma análise mensal com média geométrica sobre período de três meses, nas regiões Sul, Sudeste e Centro-Oeste, sendo que o tempo de armazenagem do leite na propriedade não ultrapasse 48 horas a $4^{\circ} \mathrm{C}$ (BRASIL, 2011). Entretanto, a Instrução
Normativa $\mathrm{N}^{\circ} 7$ prorrogou o prazo em 24 meses (BRASIL, 2016). Dessa forma, o valor máximo para este parâmetro é de $3,0.10^{5} \mathrm{UFC} / \mathrm{mL}$.

Quanto aos padrões físico-químicos para o leite cru refrigerado, o Decreto 9.013/2017 dispõe que devem ser: mínimo $3 \mathrm{~g} / 100 \mathrm{~g}$ de matéria gorda, mínimo $11,4 \mathrm{~g} / 100 \mathrm{~g}$ de extrato seco, a densidade deve estar entre 1,028 a $1,03415 / 15^{\circ} \mathrm{C} \mathrm{g} / \mathrm{mL}$, a acidez titulável pode variar entre 0,14 a $0,18 \mathrm{~g}$ de 
ácido lático/100 mL, e mínimo $2,9 \mathrm{~g} / 100 \mathrm{~g}$ para proteína (BRASIL, 2017). O pH normal do leite cru de vacas pode variar de 6,4 a 6,8 (Venturini et al., 2007).

Tabela 2. Resultados físico-químicos no leite cru refrigerado durante o tempo de armazenamento na propriedade.

\begin{tabular}{|c|c|c|c|c|c|c|c|c|c|c|c|c|}
\hline \multirow{2}{*}{$\mathbf{P}$} & \multicolumn{2}{|c|}{ pH } & \multicolumn{2}{|c|}{ Densidade } & \multicolumn{2}{|c|}{ Acidez Dornic } & \multicolumn{2}{|c|}{ Extrato Seco } & \multicolumn{2}{|c|}{ Gordura } & \multicolumn{2}{|c|}{ Proteína } \\
\hline & $\mathbf{A}$ & D & $\mathbf{A}$ & D & $\mathbf{A}$ & D & $\mathbf{A}$ & D & $\mathbf{A}$ & D & $\mathbf{A}$ & D \\
\hline 1 & $\begin{array}{c}6,79 \\
\pm \\
0,035 \mathrm{a}\end{array}$ & $\begin{array}{c}5,87 \\
\pm \\
0,106 \mathrm{~b}\end{array}$ & $\begin{array}{c}1,029 \\
\pm \\
0 \mathrm{a}\end{array}$ & $\begin{array}{c}1,021 \\
\pm \\
0 \mathrm{~b}\end{array}$ & $\begin{array}{c}19,5 \\
\pm \\
2,12 \mathrm{a}\end{array}$ & $\begin{array}{c}32,5 \\
\pm \\
3,53 \mathrm{~b}\end{array}$ & $\begin{array}{c}20,61 \\
\pm \\
0,57 \mathrm{a}\end{array}$ & $\begin{array}{c}24,09 \\
\pm \\
0,12 \mathrm{~b}\end{array}$ & $\begin{array}{c}5,3 \\
\pm \\
0,42 \mathrm{a}\end{array}$ & $\begin{array}{c}8 \\
\pm \\
0 \mathrm{~b}\end{array}$ & $\begin{array}{c}1,96 \\
\pm \\
0 \mathrm{a}\end{array}$ & $\begin{array}{c}1,82 \\
\pm \\
0,06 \mathrm{a}\end{array}$ \\
\hline 2 & $\begin{array}{c}6,27 \\
\pm \\
0,042 \mathrm{a}\end{array}$ & $\begin{array}{c}6,62 \\
\pm \\
0,042 \mathrm{~b}\end{array}$ & $\begin{array}{c}1,02 \\
\pm \\
0 \mathrm{a}\end{array}$ & $\begin{array}{c}1,028 \\
\pm \\
0 \mathrm{~b}\end{array}$ & $\begin{array}{c}28,5 \\
\pm \\
0,70 \mathrm{a}\end{array}$ & $\begin{array}{c}20,5 \\
\pm \\
0,7 \mathrm{~b}\end{array}$ & $\begin{array}{c}26,37 \\
\pm \\
1,37 \mathrm{a}\end{array}$ & $\begin{array}{c}35,38 \\
\pm \\
0,01 \mathrm{~b}\end{array}$ & $\begin{array}{c}8 \\
\pm \\
0 \mathrm{a}\end{array}$ & $\begin{array}{c}4,9 \\
\pm \\
0,56 \mathrm{~b}\end{array}$ & $\begin{array}{c}1,83 \\
\pm \\
0 \mathrm{a}\end{array}$ & $\begin{array}{c}1,96 \\
\pm \\
0 \mathrm{a}\end{array}$ \\
\hline 3 & $\begin{array}{c}6,8 \\
\pm \\
0,007 \mathrm{a}\end{array}$ & $\begin{array}{c}6,65 \\
\pm \\
0,077 \mathrm{a}\end{array}$ & $\begin{array}{c}1,029 \\
\pm \\
0 \mathrm{a}\end{array}$ & $\begin{array}{c}1,028 \\
\pm \\
0 \mathrm{a}\end{array}$ & $\begin{array}{c}20 \\
\pm \\
0 \mathrm{a}\end{array}$ & $\begin{array}{c}18,5 \\
\pm \\
0,7 \mathrm{a}\end{array}$ & $\begin{array}{c}19,87 \\
\pm \\
0,03 \mathrm{a}\end{array}$ & $\begin{array}{c}30,15 \\
\pm \\
0,21 \mathrm{~b}\end{array}$ & $\begin{array}{c}5,75 \\
\pm \\
0,35 \mathrm{a}\end{array}$ & $\begin{array}{c}3,75 \\
\pm \\
0,35 \mathrm{~b}\end{array}$ & $\begin{array}{c}2,02 \\
\pm \\
0,03 \mathrm{a}\end{array}$ & $\begin{array}{c}2,05 \\
\pm \\
0 \mathrm{a}\end{array}$ \\
\hline 4 & $\begin{array}{c}6,87 \\
\pm \\
0,056 \mathrm{a}\end{array}$ & $\begin{array}{c}6,95 \\
\pm \\
0,063 \mathrm{a}\end{array}$ & $\begin{array}{c}1,031 \\
\pm \\
0 \mathrm{a}\end{array}$ & $\begin{array}{c}1,032 \\
\pm \\
0 \mathrm{a}\end{array}$ & $\begin{array}{c}20,5 \\
\pm \\
0,70 \mathrm{a}\end{array}$ & $\begin{array}{c}20,5 \\
\pm \\
0,7 \mathrm{a}\end{array}$ & $\begin{array}{c}19,68 \\
\pm \\
0,01 \mathrm{a}\end{array}$ & $\begin{array}{c}17,46 \\
\pm \\
0,01 \mathrm{a}\end{array}$ & $\begin{array}{c}4 \\
\pm \\
0 \mathrm{a}\end{array}$ & $\begin{array}{c}4 \\
\pm \\
0,28 \mathrm{a}\end{array}$ & $\begin{array}{c}2,07 \\
\pm \\
0,09 \mathrm{a}\end{array}$ & $\begin{array}{c}2,23 \\
\pm \\
0 \mathrm{~b}\end{array}$ \\
\hline 5 & $\begin{array}{c}7,03 \\
\pm \\
0,049 \mathrm{a}\end{array}$ & $\begin{array}{c}6,91 \\
\pm \\
0,042 \mathrm{a}\end{array}$ & $\begin{array}{c}1,029 \\
\pm \\
0 \mathrm{a}\end{array}$ & $\begin{array}{c}1,029 \\
\pm \\
0 \mathrm{a}\end{array}$ & $\begin{array}{c}20 \\
\pm \\
1,41 \mathrm{a}\end{array}$ & $\begin{array}{c}20 \\
\pm \\
1,41 \mathrm{a}\end{array}$ & $\begin{array}{c}19,56 \\
\pm \\
0,76 \mathrm{a}\end{array}$ & $\begin{array}{c}26,66 \\
\pm \\
0,08 \mathrm{~b}\end{array}$ & $\begin{array}{c}4,05 \\
\pm \\
0,35 \mathrm{a}\end{array}$ & $\begin{array}{c}3,75 \\
\pm \\
0,07 \mathrm{a}\end{array}$ & $\begin{array}{c}2,09 \\
\pm \\
0 \mathrm{a}\end{array}$ & $\begin{array}{c}2,02 \\
\pm \\
0,03 \mathrm{a}\end{array}$ \\
\hline 6 & $\begin{array}{c}6,84 \\
\pm \\
0,042 \mathrm{a}\end{array}$ & $\begin{array}{c}6,9 \\
\pm \\
0,063 \mathrm{a}\end{array}$ & $\begin{array}{c}1,03 \\
\pm \\
0 \mathrm{a}\end{array}$ & $\begin{array}{c}1,03 \\
\pm \\
0 \mathrm{a}\end{array}$ & $\begin{array}{c}20 \\
\pm \\
1,41 \mathrm{a}\end{array}$ & $\begin{array}{c}19,5 \\
\pm \\
0,70 \mathrm{a}\end{array}$ & $\begin{array}{c}23,45 \\
\pm \\
1,34 \mathrm{a}\end{array}$ & $\begin{array}{c}21,12 \\
\pm \\
0,53 \mathrm{a}\end{array}$ & $\begin{array}{c}4,25 \\
\pm \\
0,07 \mathrm{a}\end{array}$ & $\begin{array}{c}3,9 \\
\pm \\
0 \mathrm{a}\end{array}$ & $\begin{array}{c}2,07 \\
\pm \\
0,02 \mathrm{a}\end{array}$ & $\begin{array}{c}2,09 \\
\pm \\
0 \mathrm{a}\end{array}$ \\
\hline 7 & $\begin{array}{c}6,51 \\
\pm \\
0,049 \mathrm{a}\end{array}$ & $\begin{array}{c}6,77 \\
\pm \\
0,035 b\end{array}$ & $\begin{array}{c}1,03 \\
\pm \\
0 \mathrm{a}\end{array}$ & $\begin{array}{c}1,031 \\
\pm \\
0 \mathrm{a}\end{array}$ & $\begin{array}{c}17,75 \\
\pm \\
0,35 \mathrm{a}\end{array}$ & $\begin{array}{c}17 \\
\pm \\
1,41 \mathrm{a}\end{array}$ & $\begin{array}{c}19,8 \\
\pm \\
0,28 \mathrm{a}\end{array}$ & $\begin{array}{c}17,56 \\
\pm \\
0,70 \mathrm{a}\end{array}$ & $\begin{array}{c}4,45 \\
\pm \\
0,35^{\mathrm{a}}\end{array}$ & $\begin{array}{c}4,6 \\
\pm \\
0 \mathrm{a}\end{array}$ & $\begin{array}{c}2,22 \\
\pm \\
0,06 \mathrm{a}\end{array}$ & $\begin{array}{c}2,36 \\
\pm \\
0,06 \mathrm{a}\end{array}$ \\
\hline 8 & $\begin{array}{c}6,65 \\
\pm \\
0 \mathrm{a}\end{array}$ & $\begin{array}{c}6,67 \\
\pm \\
0,021 \mathrm{a}\end{array}$ & $\begin{array}{c}1,03 \\
\pm \\
0 \mathrm{a}\end{array}$ & $\begin{array}{c}1,03 \\
\pm \\
0 \mathrm{a}\end{array}$ & $\begin{array}{c}19 \\
\pm \\
0 \mathrm{a}\end{array}$ & $\begin{array}{c}17,5 \\
\pm \\
0,70 \mathrm{a}\end{array}$ & $\begin{array}{c}18,64 \\
\pm \\
0,01 \mathrm{a}\end{array}$ & $\begin{array}{c}20,11 \\
\pm \\
0,15 \mathrm{a}\end{array}$ & $\begin{array}{c}4 \\
\pm \\
0 \mathrm{a}\end{array}$ & $\begin{array}{c}3,8 \\
\pm \\
0,28 \mathrm{a}\end{array}$ & $\begin{array}{c}2 \\
\pm \\
0 \mathrm{a}\end{array}$ & $\begin{array}{c}2,14 \\
\pm \\
0 \mathrm{a}\end{array}$ \\
\hline 9 & $\begin{array}{c}6,91 \\
\pm \\
0,077 \mathrm{a}\end{array}$ & $\begin{array}{c}6,8 \\
\pm \\
0,028 \mathrm{a}\end{array}$ & $\begin{array}{c}1,031 \\
\pm \\
0 \mathrm{a}\end{array}$ & $\begin{array}{c}1,031 \\
\pm \\
0 \mathrm{a}\end{array}$ & $\begin{array}{c}16,5 \\
\pm \\
0,70 \mathrm{a}\end{array}$ & $\begin{array}{c}16 \\
\pm \\
0 \mathrm{a}\end{array}$ & $\begin{array}{c}29,98 \\
\pm \\
1,52 \mathrm{a}\end{array}$ & $\begin{array}{c}22,38 \\
\pm \\
0 \mathrm{~b}\end{array}$ & $\begin{array}{c}4,5 \\
\pm \\
0 \mathrm{a}\end{array}$ & $\begin{array}{c}4 \\
\pm \\
0 \mathrm{a}\end{array}$ & $\begin{array}{c}1,98 \\
\pm \\
0,02 \mathrm{a}\end{array}$ & $\begin{array}{c}2,21 \\
\pm \\
0,03 \mathrm{~b}\end{array}$ \\
\hline 10 & $\begin{array}{c}6,81 \\
\pm \\
0,056 \mathrm{a}\end{array}$ & $\begin{array}{c}6,87 \\
\pm \\
0,063 \mathrm{a}\end{array}$ & $\begin{array}{c}1,031 \\
\pm \\
0 \mathrm{a} \\
\end{array}$ & $\begin{array}{c}1,031 \\
\pm \\
0 \mathrm{a}\end{array}$ & $\begin{array}{c}15,5 \\
\pm \\
0,70 \mathrm{a} \\
\end{array}$ & $\begin{array}{c}14,5 \\
\pm \\
0,70 \mathrm{a} \\
\end{array}$ & $\begin{array}{c}27,19 \\
\pm \\
2,03 \mathrm{a} \\
\end{array}$ & $\begin{array}{c}30,86 \\
\pm \\
1,49 \mathrm{~b} \\
\end{array}$ & $\begin{array}{c}3 \\
\pm \\
0 \mathrm{a} \\
\end{array}$ & $\begin{array}{c}3,8 \\
\pm \\
0,28 \mathrm{a} \\
\end{array}$ & $\begin{array}{c}2,02 \\
\pm \\
0,03 \mathrm{a} \\
\end{array}$ & $\begin{array}{c}2,23 \\
\pm \\
0 \mathrm{~b} \\
\end{array}$ \\
\hline
\end{tabular}

* Propriedades. **Densidade $\left(\mathrm{g} / \mathrm{mL}\right.$ a $\left.15^{\circ} \mathrm{C}\right)$; Acidez Dornic $\left({ }^{\circ} \mathrm{D}\right)$; Proteína $(\mathrm{g} / 100 \mathrm{~g})$; A: Antes. D: Depois.

Valores submetidos ao teste de Tukey a $5 \%$ de probabilidade.

Quanto à forma de armazenamento do leite nas propriedades, as de número 3 a 10 possuíam refrigeração por tanque de expansão direta. Em contrapartida, as propriedades 1 e 2 possuíam refrigeração por tanque de imersão e freezer horizontal, respectivamente. É importante ressaltar que, mesmo não apresentando nenhuma contagem e nenhuma alteração nos parâmetros físicoquímicos fora dos limites estabelecidos pela legislação e literatura, a refrigeração do leite por freezer horizontal não é permitida segundo o Regulamento Técnico de Identidade e Qualidade RTIQ do leite cru (BRASIL, 2011).
Quanto às contagens de aeróbios mesófilos, o crescimento microbiano durante o tempo de armazenamento na propriedade não ultrapassou $o$ estabelecido pelo RTIQ do leite cru em nenhuma das amostras. Entretanto, na propriedade 1 houve um aumento significativo $(\mathrm{P}<0,05)$ na contagem de aeróbios mesófilos no período de 48 horas. A amostra da propriedade 1 também apresentou diminuição significativa do $\mathrm{pH}$ (de 6,79 para 5,87 ) e aumento de acidez Dornic (de 19,5 para 32,5 graus Dornic). Estas alterações estão relacionadas ao crescimento de microrganismos presentes no leite, que utilizam a lactose como substrato e 
consequentemente produzem ácido lático (Venturini et al., 2007).

Os valores de acidez obtidos nas análises, tanto antes quanto depois, foram superiores ao recomendado em legislação, em $65 \%$ das amostras (13). Que pode estar relacionado ao início de processo de fermentação, devido a presença de microrganismos, mas também a outros fatores, como leite do início da lactação, leite com colostro e a raça do animal (Rodrigues et al, 1995; Barros, 2018).

Ao analisarem amostras de leite cru refrigerado em tanques de imersão e expansão direta na região Oeste do Paraná, Bersot et al. (2009) observaram que as contagens de mesófilos foram estatisticamente menores nas amostras obtidas de tanques de expansão quando comparadas as de tanque de imersão.

Isto pode justificar a contagem maior destas bactérias na amostra da propriedade 1 com relação as demais, pois supõe-se que o tempo para alcançar a temperatura de refrigeração é maior especialmente quando misturadas quantidades de leite de ordenhas posteriores, permitindo assim o crescimento destes microrganismos.

Pin et al. (2014) em pesquisa no município de Dois Vizinhos, região Sudoeste do Paraná, encontraram contagem de aeróbios mesófilos de $6,0.10^{6} \mathrm{UFC} / \mathrm{mL}$ no leite submetido à ordenha manual e refrigeração na geladeira. Ressaltando a ineficácia de outras formas de refrigeração do leite para o controle da multiplicação desses microrganismos.

Quanto as bactérias psicrotróficas, Zacharov e Helpern (2007) sugerem que o limite máximo de bactérias psicrotróficas, para não interferir na qualidade do leite e de seus produtos, deve ser de até $10^{6} \mathrm{UFC} / \mathrm{mL}$, pois a partir desse ponto do crescimento bacteriano se inicia a produção de enzimas proteolíticas e lipolíticas.

Do total das amostras, apenas três delas, pertencentes as propriedades 1,6 e 7, ultrapassaram a contagem de microrganismos psicrotróficos recomendada por Zacharov e Helpern (2007), adotado no estudo de Ângelo et al. (2014). Destas, duas foram do leite armazenado na propriedade por 48 horas, demonstrando que houve crescimento microbiano durante esse período. Além disso, na propriedade 1 foi encontrado aumento significativo $(\mathrm{P}<0,05)$ entre as coletas e a maior contagem entre todas as amostras avaliadas $\left(3,4 \cdot 10^{6} \mathrm{UFC} / \mathrm{mL}\right)$. Ainda, nesta amostra o número de psicrotróficos foi maior que de aeróbio mesófilos.

Santana et al. (2004), no município de Londrina-PR, observaram que a contagem de microrganismos aeróbios mesófilos foi menor que a contagem de microrganismos psicrotróficos. Os autores afirmam que esse fato demonstra como a contagem de mesófilos subestima a carga microbiana total do leite.

Os autores Santana et al. (2004) ainda observaram os pontos de contaminação do leite no processo de ordenha. Conseguiram identificar altas contagens de bactérias psicrotróficas no tanque de resfriamento, variando de $10^{5}$ a $10^{6} \mathrm{UFC} / \mathrm{mL}$. Os autores acreditam que essas altas contagens estejam relacionadas à presença de água residual nos equipamentos. Já em pesquisa realizada em duas regiões do estado de Santa Catarina, Reche et al. (2015) não observaram crescimento de bactérias psicrotróficas no leite armazenado nas propriedades por 48 horas.

Quanto a capacidade de bactérias psicrotróficas produzirem enzimas proteolíticas, Nörnberg et al. (2010) afirma que 40 a $45 \%$ das bactérias psicrotróficas são também proteolíticas. Santana et al. (2004) afirmam que a contagem de microrganismos psicrotróficos e proteolíticos encontrados no leite cru refrigerado por 12 horas é suficiente para alterar as características organolépticas e estruturais no leite e seus produtos. Ainda ressaltam a ocorrência de psicrotróficos proteolíticos no leite tipo A pasteurizado, o que indica possível recontaminação ou resistência térmica dos microrganismos (Saeki e Matsumoto, 2010).

Quanto às contagens de colônias proteolíticas, duas amostras ultrapassaram o limite de $10^{6} \mathrm{UFC} / \mathrm{mL}$ e foi observado aumento significativo $(\mathrm{P}<0,05)$ da contagem em quatro propriedades (1, 6, 7 e 8). Já quanto às colônias lipolíticas, cinco amostras apresentaram contagens acima desse limite e três propriedades $(1,6$ e 10) obtiveram aumento significativo $(\mathrm{P}<0,05)$ da contagem. Esse fato aumenta o risco de que o leite produzido possa sofrer uma deterioração por essas enzimas durante o período de armazenagem cru e, provavelmente, após o tratamento térmico (VidalMartins et al., 2005).

Santana et al. (2004) observaram que as maiores contagens foram nos leites tipo A e B refrigerados por 12 horas, sendo de 9,7.10 $\mathrm{UFC} / \mathrm{mL}$ para ambos. No trabalho de Moreira e Montanhini (2014) foram identificados pontos de 
contaminação do leite por microrganismos lipolíticos e proteolíticos em propriedades leiteiras na região metropolitana de Curitiba - PR. Das amostras coletadas no tanque de resfriamento, $50 \%$ apresentaram atividade lipolítica e nenhuma atividade proteolítica. Comparando aos resultados encontrados no trabalho, também se obteve maiores resultados em contagens de colônias lipolíticas do que proteolíticas, utilizando o limite de $1,0.10^{6} \mathrm{UFC} / \mathrm{mL}$. Os autores sugerem que essa alta contaminação pode ser atribuída à deficiência de higienização do tanque de resfriamento e presença de água residual, que favorece $o$ crescimento desses microrganismos (Hass, 2001).

Apesar da maior parte das propriedades avaliadas apresentarem os padrões microbiológicos dentro do recomendado, deve-se acompanhar através de análises a qualidade higiênico-sanitária do leite produzido. A importância disso se dá pela futura redução nos valores para contagem de aeróbios mesófilos, já prevista na legislação, e também para a manutenção da qualidade físico-química do leite e seus produtos.

Quanto ao extrato seco, todos os valores se mantiveram dentro do estabelecido, entretanto, na propriedade 9 ocorreu uma diminuição significativa durante o período de armazenagem $(\mathrm{P}<0,05)$. Quanto à gordura, apenas nas propriedades 2 e 3 houve uma diminuição significativa durante o período de armazenagem do leite na propriedade $(\mathrm{P}<0,05)$. Quanto à proteína, nenhuma das amostras se enquadrou no estabelecido na legislação e nenhuma apresentou diminuição dos teores de proteína significativa $(\mathrm{P}>0,05)$.

A composição físico-química do leite pode sofrer alterações na presença de elevadas contagens de bactérias aeróbias mesófilas, de bactérias psicrotróficas e de suas enzimas proteolíticas e lipolíticas. Com o aumento da contagem bacteriana total (CBT), Vargas et al. (2013) observou que houve uma diminuição nos teores de lactose e sólidos não gordurosos e Andrade et al. (2009) observaram uma diminuição nos teores de gordura.

\section{Conclusão}

Conclui-se que é de grande importância a realização de análises para estimar microrganismos deteriorantes do leite e as consequências de sua presença. Apesar das contagens de aeróbios mesófilos não ultrapassarem o limite estabelecido em legislação, houve crescimento de psicrotróficos, proteolíticos e lipolíticos em amostras de leite. Além disso, foram observadas alterações físico-químicas, como acidificação, no leite armazenado na propriedade.

\section{Conflito de Interesse}

Os autores declaram não existir conflito de interesse.

\section{Referências}

Andrade, U.V.C.; Hartmann, W.; Masson, M.L. Isolamento microbiológico, contagem de células somáticas e contagem bacteriana total em amostras de leite. Ars Veterinaria, 25(3): 129-135, 2009.

Ângelo, F.F.; Ribeiro, C.D.S.; Oliveira, L.D.; Araujo, T.F.D.; Cardarelli, H.R. Bactérias psicrotróficas em leite cru refrigerado. Revista Científica de Medicina Veterinária, 12(22): 1-14, 2014.

Barros, L. Transtornos metabólicos que afetam a qualidade do leite. In: González, F. Doze leituras em bioquímica clínica veterinária. Porto Alegre: Faculdade de Veterinária, Universidade Federal do Rio Grande do Sul. 159p. 2018.

Bersot, L.D.S.; Barcellos, V.C.; Fujisawa, F.M.; Pereira, J.G.; Maziero, M. T. Influência do sistema de estocagem na propriedade rural sobre a qualidade microbiológica do leite in natura. Revista do Instituto de Laticínios “Cândido Tostes", 64(371): 35-39, 2009.

BRASIL. Ministério da Agricultura, Pecuária e Abastecimento. Instrução Normativa $\mathbf{N}^{\circ} \mathbf{5 1}$, de 18 de setembro de 2002. Regulamentos Técnicos de Produção, Identidade e Qualidade do Leite tipo A, tipo B, tipo C, Leite Pasteurizado e Cru Refrigerado; Coleta de Leite Cru Refrigerado e seu Transporte a Granel. Diário Oficial da República Federativa do Brasil, Brasília, 20 set. 2002. Seção 1, p. 8-13.

BRASIL. Ministério da Agricultura, Pecuária e Abastecimento. Instrução Normativa $\mathbf{N}^{\mathbf{0}} \mathbf{6 2}$, de 29 de dezembro de 2011. Regulamento Técnico de Produção, Identidade e Qualidade do Leite tipo A, Leite Cru Refrigerado, Leite Pasteurizado e Coleta de Leite Cru Refrigerado e seu Transporte a Granel. Diário Oficial da República Federativa do Brasil, Brasília, 30 dez. 2011. Seção 1, p. 6. 
BRASIL. Ministério da Agricultura, Pecuária e Abastecimento. Instrução Normativa $\mathbf{N}^{\mathbf{0}}$ 62, de 26 de agosto de 2003. Oficializa os Métodos Analíticos Oficiais para Análises Microbiológicas para Controle de Produtos de Origem Animal e Água. Diário Oficial da República Federativa do Brasil, Brasília, 18 set. 2003. Seção 1, p. 14.

BRASIL. Ministério da Agricultura, Pecuária e Abastecimento. Instrução Normativa $\mathbf{N}^{\mathbf{0}} \mathbf{6 8}$, de 12 de dezembro de 2006. Oficializa os Métodos Analíticos Oficiais Físico-Químicos, para Controle de Leite e Produtos Lácteos, em conformidade com o anexo desta Instrução Normativa, determinando que sejam utilizados nos Laboratórios Nacionais Agropecuários. Diário Oficial da República Federativa do Brasil, Brasília, 14 dez. 2006. Seção 1, p. 8.

BRASIL. Ministério da Agricultura, Pecuária e Abastecimento. Regulamento de Inspeção Industrial e Sanitária de Produtos de Origem Animal. Brasília, 2017.

BRASIL. Ministério da Agricultura, Pecuária e Abastecimento. Secretaria de Defesa Agropecuária. Instrução Normativa $\mathbf{N}^{\mathbf{0}} \mathbf{7}$, de 03 de maio de 2016. Diário Oficial da República Federativa do Brasil, Brasília, 04 mai. 2016. Seção 1, p. 11.

Castanheira, A.C.G. Controle de qualidade de leite e derivados: manual básico comentado. 2 ed. São Paulo: Cap-Lab. 2012. 368p.

Citadin, A.S.; Pozza, M.S.D.S.; Pozza, P.C.; Nunes, R.V.; Borsatti, L.; Mangoni, J. Qualidade microbiológica de leite cru refrigerado e fatores associados. Revista Brasileira de Saúde e Produção Animal, 10(1): 52-59, 2009.

Cousin, M.A. Presence and activity of psychrotrophic microorganisms in milk and dairy products: a review. Journal of Food Protection, 45(1): 172-207. 1982.

Ferreira, D.F. Sisvar: A Guide for its Bootstrap procedures in multiple comparisons. Ciência e Agrotecnologia, 38(2): 109-112. 2014.

Griffiths, M.W. Effects of temperature and milk fat on extracellular enzyme synthesis by psychrotrophic bacteria during growth in milk. Milchwissenschaft, 44(1): 539-443. 1989.

Hass, M. Lipolytic microorganisms. In: Downs, F.P.; Ito, K. Compendium of methods for the microbiological examination of foods. 4.ed. Washington DC: American Public Health Association, 2001. p.175-181.

IBGE. Pesquisa Pecuária Municipal. 2015. Disponível em: http://www.ibge.gov.br/home/estatistica/econ omia/ppm/2015/. Acesso em: 07 ago. 2017.

IPARDES. Caracterização sócio-econômica da produção leiteira no Paraná. Curitiba: IPARDES, 2008. Disponível em: http://www.ipardes.gov.br/biblioteca/docs/su mario_executivo_atividade_leiteira_parana.p df. Acesso em: 10 jan. 2018.

Izidoro, T.B.; Pereira, J.G.; Soares, V.M.; Spina, T.L.B.; Pinto, J.P.D.A.N. Atividade proteolítica de bactérias psicrotróficas em leites estocados em diferentes temperaturas. Revista Ceres, 60(4): 452-457. 2013

Marcy, J.A.; Pruett, W.P. Proteolytic microorganisms. In: Downs, F.P.; Ito K. Compendium of methods for the microbiological examination of foods. 4ed. Washington DC: American Public Health Association, 2001. p.175-181.

Moreira, N.V.; Montanhini, M.T.M. Milk contamination in the milking by proteolytic and lipolytic microorganisms. Revista Brasileira de Higiene e Sanidade Animal, 8(2): 29-38, 2014.

Nörnberg, M.F.B.L.; Friedrich, R.S.C.; Weiss, R.D.N.; Tondo, E.C.; Brandelli, A. Proteolytic activity among psychrotrophic bacteria isolated from refrigerated raw milk. International Journal Of Dairy Technology, 63(1): 41-46, 2010.

Pin, E.A.; Mantelli, C.; Bertoldo, E. Ordenha e refrigeração ineficientes impactam na qualidade do leite. Faz Ciência, 16(24): 4157, 2014

Pinto, C.L.O.; Machado, S.G.; Martins, M.L.; Vanetti, M.C.D. Qualidade microbiológica doleite cru refrigerado e isolamento de bactérias psicrotróficas proteolíticas. Ciência e Tecnologia de Alimentos, 26(3): 645-651, 2006.

Reche, N.L.M.; Neto, A.T.; D’Ovideo, L.; Felipus, N.C.; Pereira, L.C.; Cardozo, L.L.; Lorenzetti, R.G.; Picinin, L.C.A. Multiplicação microbiana no leite cru armazenado em tanques de expansão direta. Ciência Rural, 45(5): 828-834, 2015.

Reis, K.T.M.G.; Souza, C.H.B.D.; Santana, E.H.W.D.; Roig, S.M. Qualidade 
Microbiológica do Leite Cru e Pasteurizado Produzido no Brasil: Revisão. UNOPAR Científica Ciências Biológicas e da Saúde. 15(ESP):411-21. 2013.

Rodrigues, R.; Fonseca, L.M.; Souza, M.R. Acidez do leite. Caderno Técnico da Escola de Veterinária UFMG, 1(13): 63-72, 1995.

Saeki, E.K; Matsumoto, L.S. Contagem de mesófilos e psicrotróficos em amostras de leite pasteurizado e UHT. Revista do Instituto de Laticínios Cândido Tostes, 65(377): 29-35, 2010.

Santana, E.H.W.D.; Beloti, V.; Müller, E.E.; Ferreira, M.D.A.; Moraes, L.B.D.; Pereira, M.S.; Gusmão, V.V. Contaminação do leite em diferentes pontos da produção leiteira: ii) microrganismos mesófilos, psicrotróficos e proteolíticos. Semina:

Ciências

Agrárias, 25(4): 349-358, 2004.

SEABa. Leite - Análise da Conjuntura Agropecuária. Ano 2016/17. 2017. Disponível em: <http://www.agricultura.pr.gov.br/arquivos/F ile/deral/Prognosticos/2017/leite_2016_17.pd f>. Acesso em: 07 ago. 2017.

SEABb. Números da Pecuária Paranaense: ano de 2017. 2017. Disponível em:
<http://www.agricultura.pr.gov.br/arquivos/F ile/deral/nppr.pdf >. Acesso em: 07 ago. 2017. Silva, N.; Junqueira, V.C.A.; Silveira, N.F.D.A.; Taniwaki, M.H.; Gomes, R.A.R.; Okazaki, M.M. Manual de métodos de análise microbiológica de alimentos. 3. ed. São Paulo: Livraria Varela, 2007. 536p.

Vargas, D.P.D.; Nörnberg, J.L.; Mello, R.D.O.; Sheibler, R.B.; Milani, M.P.; Mello, F.C.B. Correlações entre contagem bacteriana total $\mathrm{e}$ parâmetros de qualidade do leite. Revista Brasileira de Ciência Veterinária, 20(4): 241-247, 2013.

Venturini, K.S.; Sarcinelli, M.F.; Silva, L.C.D. Características do leite. UFES: Pró-Reitoria de Extensão, 2007. 6p.

Vidal-Martins, A.M.C.; Rossi Júnior, O.D.; Bürger, K.P.; Cardozo, M.V.; Salloti, B.M.; Cortez, A.L.C. Evolução do índice proteolítico e do comportamento reológico durante a vida de prateleira de leite UAT/UHT. Ciência e Tecnologia de Alimentos, 25(4): 698-704, 2005.

Zacharov, E.H.; Helpern, M. Culturable psychrotrophic bacterial communities in raw milk and their proteolytic and lipolytic traits. Applied and Environmental Microbiology, 73(1): 7162-7168, 2007. 